\title{
DESKRIPSI EFEKTIVITAS KEGIATAN PRAKTIKUM DALAM PERKULIAHAN KIMIA DASAR MAHASISWA TEKNIK
}

\author{
Eliyarti $^{1}$, Chichi Rahayu ${ }^{2}$ \\ 1,2 Fakultas Teknik \& Perencanaan, Universitas Ekasakti, Padang, Indonesia
}

\section{A R T I C L E I N F O \\ Article history: \\ Received 28 Agustus 2019 \\ Received in revised form 1 \\ Oktober 2019 \\ Accepted 2 Oktober 2019 \\ Available online 12 Oktober 2019}

Kata Kunci

Praktikum; Kimia Dasar; DeskriptifKualitatif

\begin{abstract}
A B S T R A K
Penelitian ini bertujuan untuk mendeskripsikan efektivitas kegiatan praktikum dalam perkuliahan kimia dasar mahasiswa teknik. Jenis penelitian ini deskriptif kualitatif. Populasi penelitian ini mahasiswa tingat I Fakultas Teknik dan Perencanaan Universitas Ekasakti semester ganjil 2017/2018 pada mata kuliah Kimia Dasar. Pengambilam sampel menggunakan teknik simple random sampling. Instrumen pengumpulan data menggunakan lembar pengamatan dan kuisioner. Lembar pengamatan digunakan untuk memperoleh informasi selama kegiatan praktikum berlangsung. Kuisioner digunakan untuk memperoleh data perilaku yang dilakukan mahasiswa sebelum praktikum, saat praktikum, dan setelah praktikum. Berdasarkan hasil penelitian diperoleh sebelum mengikuti kegiatan praktikum Kimia Dasar mahasiswa masih kurang mempersiapkan diri, yaitu hanya $28,57 \%$ mahasiswa membaca modul sebelum melakukan praktikum, $37,14 \%$ mahasiswa mengerjakan tugas pendahuluan dan 21,43\% mahasiswa yang menjaga kesiapan fisik (istirahat cukup dan sarapan sebelum praktikum), ke]etika praktikum Kimia Dasar berlangsung mahasiswa yang datang tepat waktu $42,73 \%$, $68,7 \%$ mahasiswa memahami prosedur percobaan, namun $27,27 \%$ mahasiswa yang dapat mengerjakan praktikum dengan benar sesuai prosedur, Setelah praktikum selesai mahasiswa yang menyegerakan pengerjaan laporan praktikum masih rendah hanya 17,14\%, dan mahasiswa yang memperoleh nilai laporan praktikum > 75 sebesar 39,39\%. Hal ini menunjukan mahasiswa masih kurang memotivasi diri dalam kegiatan praktikum sehingga diperlukan perbaikan cara belajar kedepannya.
\end{abstract}

\section{PENDAHULUAN}

Pendidikan merupakan usaha sadar manusia untuk merubah dirinya ke arah yang lebih baik (Zakirman, Lufri, \& Khairani, 2018). Konteks pendidikan meliputi proses perkembangan pribadi, proses sosial, serta menjadi wadah dalam mewariskan budaya. Pendidikan dapat memunculkan sikap-sikap dan potensi yang bersifat positif dalam diri manusia. Karakter, sifat serta watak seorang individu dapat dibentuk oleh lingkungan khususnya lingkungan pendidikan (Zakirman, 2017). Selain itu, peningkatan mutu pendidikan merupakan suatu keharusan bagi bangsa Indonesia di era globalisasi. Hal ini tidak terlepas dari sumber daya manusia yang berkualitas sehingga dapat bersaing dengan bangsa lainnya. Bidang pendidikan memegang peranan penting dan strategis sebab merupakan sebuah wahana untuk meningkatkan kualitas sumber daya manusia (Zakirman \& Rahayu, 2018).

\footnotetext{
${ }^{1}$ Corresponding author.

E-mail : rahayuchichi@gmail.com, eliyarti58@gmail.com
} 
Dalam dunia pendidikan, kimia dikenal sebagai salah satu cabang sains. Menurut Pratono, Sumarti, \& Wijayati (2018), kimia pada dasarnya adalah cara untuk mencari tahu dan memahami sifat yang sistematis. Kimia diajarkan tidak hanya dengan memberikan pemahaman tentang gagasan, fakta, konsep, prinsip, tetapi juga penemuan melalui proses pencarian dengan tindakan nyata. Ada dua hal yang berkaitan dengan kimia yang tidak bisa dipisahkan, yaitu kimia sebagai produk (pengetahuan kimia yang berupa fakta, konsep, prinsip, hukum, dan teori) dan kimia sebagai proses yaitu kerja ilmiah (Sari, Dayana, \& Farida, 2018).

Kimia Dasar merupakan mata kuliah umum yang diprogramkan pada awal semester, karena erat kaitannya dengan disiplin ilmu yang lain (Arianti, Qaddafi, \& Zulkarnaim, 2017) kimia dasar memerlukan kegiatan praktikum. Praktikum merupakan bagian dari pengajaran yang bertujuan agar mahasiswa mendapat kesempatan untuk menguji dan melaksanakan dalam keadaan nyata apa yang diperoleh dalam teori. Kegiatan praktikum mempunyai tiga fungsi yaitu latihan, umpan balik,dan memperbaiki motivasi. Sebagai fungsi latihan, praktikum dapat dimanfaatkan untuk melatihkan tiga ranah kecerdasan (kognitif, psikomotor, dan afektif) secara serentak yaitu: 1)Kecerdasan intelektual (kognitif) meliputi : pendalaman teori yang telah diperoleh, berpikir kritis dan analitis, dan memecahkan masalah; 2)Kecerdasan motorik(psikomotor)meliputi: belajar memasang peralatan tertentu sehingga betul-betul berjalan dan belajar memakai peralatan/instrumen tertentu; 3)Kecerdasan emosional dan sosial (afektif) meliputi: belajar merencanakan kegiatan secara mandiri, belajar bekerja sama, berkomunikasi, dan jujur (Rudi, 2015)

Laboratorium merupakan tempat kegiatan mahasiswa, dosen, peneliti dan sebagainya, melakukan kegiatan percobaan (Raharjo \& Harjanto, 2017). Senada dengan pendapat Hofstein \& Luneet dalam Sari et al., (2018), menyatakan bahwa laboratorium membuat perkuliahan lebih bermakna, karena mahasiswa bertindak langsung dalam melakukan pengamatan atas percobaannya. Selain itu, keberadaan laboratorium dikampus merupakan keharusan pada pendidikan sains modern, salah satunya laboratorium kimia sebagai bagian dari sains.

Kegiatan praktikum yang dilakukan di perguruan tinggi akan mengembalikan peran dosen sebagai pembimbing atau fasilisator dan peserta didik sebagai pelaksana yang harus aktif bekerja bereksperimen sesuai dengan tujuannya menemukan hasil sains yang diharapkan (Lubis, Silaban, \& Jahro, 2016). Perkuliahan pada mata kuliah sains berorientasi praktis dan membutuhkan kegiatan taktis di laboratorium. Dibutuhkan pengalaman berbasis luas untuk memperluas pengetahuan mahasiswa dalam dunia yang penuh dengan pilihan dan peluang untuk memberi makna pada perkuliahan. Perkuliahan menggunakan eksperimen yang menggunakan bahan-bahan perkuliahan yang diperkaya untuk melengkapi mahasiswa dengan pengetahuan, keterampilan, sikap dan perilaku yang sesuai (Etiubon, 2017).

Penelitian terdahulu yang dilakukan Wahyudiati pada tahun 2016 menunjukan bahwa faktor yang mempengaruhi kualitas pelaksanaan praktikum Kimia Dasar menunjukkan bahwa motivasi mahasiswa mengikuti praktikum masih kurang, peran dosen dan laboran masih perlu ditingkatkan, serta ketersediaan sarana dan prasarana yang masih terbatas (Wahyudiati, 2016). Selain itu, penelitian yang dilakukan Maknum pada tahun 2015 menyatakan bahwa faktor-faktor pendukung untuk mengembangkan keterampilan laboratorium mahasiswa, antara lain keberadaan labor, alat, dan bahan praktikum, dan adanya panduan praktikum, sedangkan faktor penghambat adalah keterbatasan waktu praktikum, serta kerusakan dan keterbatasan alat. (Maknun, 2015).

Praktikum Kimia Dasar di Fakultas Teknik Universitas Ekasakti terdiri dari 8 percobaan yaitu (1) Reaksi-reaksi Kimia, (2) Perubahan Kimia dan Perubahan Fisika, (3) Koloid, (4) Kesetimbangan Kimia, (5)Kinetika Reaksi, (6)Reaksi Redoks(reduksi dan oksidasi), (7) Logam Alkali (8) Logam Alkali Tanah. Praktikum Kimia Dasar wajib diikuti semua mahasiswa Teknik tahun I. Namun, kegiatan praktikum dalam perkuliahan kimia dasar di FT Unes masih belum maksimal. Hal ini dapat dilihat dari rata-rata nilai ujjian praktikum secara klasikal adalah 71 dengan persentase mahasiswa yang lulus 41,82\% dan yang tidak lulus 49,09\%. Sebagai solusi dari permasalahan tersebut maka peneliti melakukan penelitian dengan tujuan mendeskripsikan efektivitas kegiatan praktikum dalam perkuliahan kimia dasar mahasiswa teknik.

\section{METODE}

Jenis penelitian ini adalah deksriptif kualitatif yang bertujuan untuk mendeskipsikan efektivitas kegiatan praktikum kimia dasar mahasiswa teknik. Penelitian ini dilakukan selama 4 bulan dari September hingga Desember 2018. Populasi penelitian ini adalah mahasiswa tahun I Fakultas Teknik dan Perencanaan Universitas Ekasakti dalam perkuliahan Kimia Dasar semester ganjil 2017/2018 sejumlah 108 orang. Pengambilam sampel menggunakan teknik simple random sampling. Instrumen data menggunakan lembar pengamatan dan kuisioner. Lembar pengamatan digunakan untuk memperoleh 
informasi selama kegiatan praktikum berlangsung. Kuisioner digunakan untuk memperoleh data perilaku yang dilakukan mahasiswa sebelum praktikum, saat praktikum, dan setelah praktikum.

Ringkasan fokus pertanyaan pada kuisioner yang digunakan dalam penelitian ini disajikan pada tabel 1 berikut ini:

Tabel 1. Item Pertanyaan Instrumen

No Fokus Pertanyaan

Dari 108 kuisioner yang diberikan terdapat beberapa kuisioner yang tidak lengkap. Kuisioner yang tidak lengkap pengisiannya disisihkan dan selanjutnya diambil secara acak 70 kuisioner untuk dianalisis.Selanjutnya pengamatan dilakukan dalam dua kali sesi perkuliahan.

Pengamatan dilakukan oleh dua orang observer terhadap 108 orang mahasiswa. Pada lembar pengamatan terdiri dari 6 indikator yang diamati seperti yang ditunjukan pada tabel 2 berikut.

Tabel 2. Indikator pengamatan

\begin{tabular}{cl}
\hline No & \multicolumn{1}{c}{ Indikator } \\
\hline 1 & Mengerjakan tugas pendahuluan setiap pertemuan \\
2 & Datang tepat waktu sebelum praktikum dimulai \\
3 & Mendengarkan penjelasan instruktur \\
4 & Mengerjakan praktikum dengan baik (minim kesalahan prosedur kerja) \\
5 & Mengumpulkan laporan praktikum tepat waktu (seminggu setelah paktikum \\
& dilakukan) \\
6 & Memperoleh nilai laporan parktikum $>75$ \\
\hline
\end{tabular}

\section{HASIL DAN PEMBAHASAN}

Data yang diperoleh dari penelitian ini adalah hasil analisis kuisioner yang diisi oleh 70 orang mahasiswa. Analisis dilakukan untuk setiap item pertanyaan terkait perilaku mahasiswa sebelum praktikum, saat kegiatan praktikum berlangsung, dan setelah praktikum dilakukan.

1. Persiapan sebelum praktikum

Pertanyaan tentang perilaku mahasiswa sebelum praktikum meliputi nomor 1, 2, dan 3 . Dibutuhkan persiapan sebelum melakukan praktikum Persentase tinjauan persiapan mahasiswa sebelum kegiatan praktikum disajikan pada Gambar 1 berikut. 


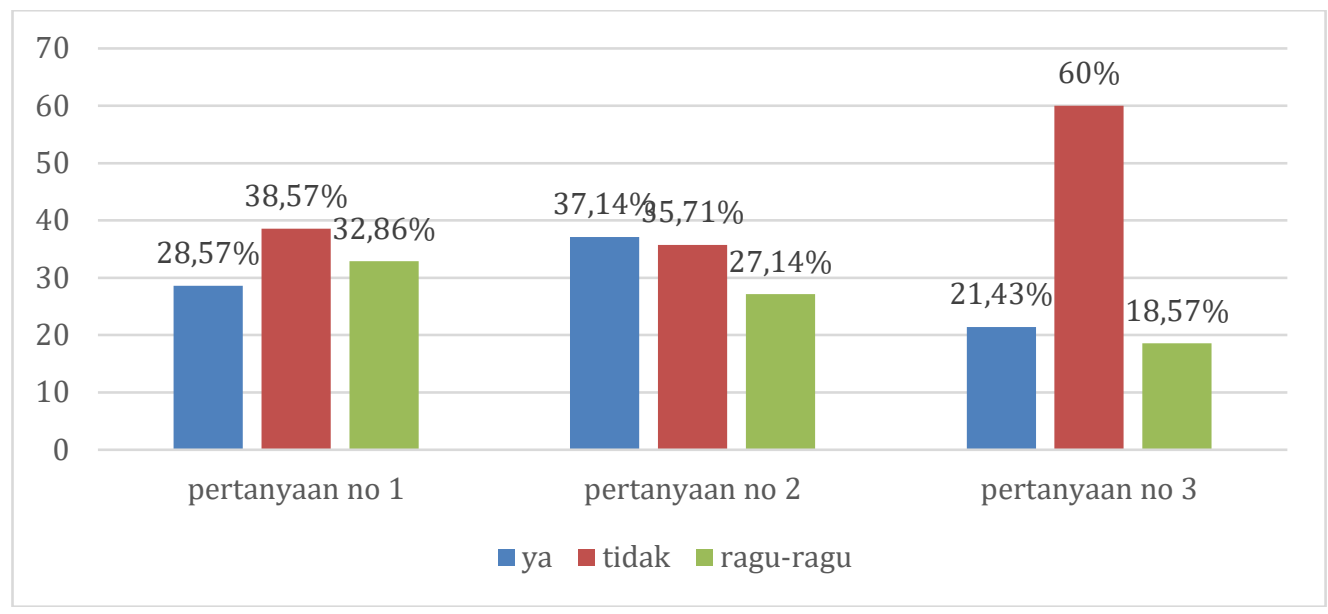

Gambar 1. Persentase Tinjauan Persiapan Mahasiswa Sebelum Kegiatan Praktikum

Pada pertanyaan pertama, persentase mahasiswa membaca modul sebelum melakukan praktikum hanya $28,57 \%$, persentase yang tidak membaca modul sebelum melakukan praktikum cukup besar $38,57 \%$ dan yang ragu-ragu $32,86 \%$. Pada pertanyaan kedua, persentase mahasiswa mengerjakan tugas pendahuluan $37,14 \%$, persentase mahasiswa yang tidak mengerjakan tugas pendahuluan $35,71 \%$ dan yang ragu-ragu $27,14 \%$. Pada pertanyaan ketiga, persentase mahasiswa yang menjaga kesiapan fisik (istirahat cukup dan sarapan sebelum praktikum) hanya $21,43 \%$, persentase mahasiswa yang tidak menjaga kesehatan fisik lebih banyak yaitu $60 \%$ dan yang ragu-ragu $18,57 \%$.

Persiapan dalam ilmu kimia dasar bukan hanya proses penyediaan peralatan, lokasi, atau bahan yang digunakan sebelum pelaksanaan percobaan. Persiapan juga merupakan kegiatan untuk menciptakan prasyarat untuk belajar, mempelajari situasi yang muncul minat dan keuntungan belajar (Copriady, 2015). Merujuk pada hasil analsis, persentase mahasiswa membaca modul sebelum melakukan praktikum lebih sedikit daripada yang tidak membaca. Padahal dengan membaca mahasiswa bisa menambah pengetahuan awal yang dibutuhkan dalam praktikum. Walaupun persentase mahasiswa mengerjakan tugas pendahuluan lebih banyak daripada yang tidak mengerjakan, namun persentase mahasiswa yang menjaga kesiapan fisik (istirahat cukup dan sarapan sebelum praktikum) hanya sedikit. Sehingga banyak diantara mahasiswa yang kesulitan konsentrasi dan terlihat tidak bersemangat ketika praktikum. Sikap tersebut dapat menjadi suatu kebiasaan dalam diri mahasiswa (Rahayu \& Festiyed, 2018). Perilaku ini menunjukan mahasiswa masih kurang mempersiapkan diri untuk mengikuti praktikum kimia dasar.

2. Ketika Kegiatan Praktikum Berlangsung

Selama kegiatan praktikum berlangsung, observer mengamati perilaku mahasiswa dan memberi penilaian pada lembar observasi. Hasil analisis lembar pengamatan disajikan pada tabel 3 berikut.

Tabel 3. Analisis lembar pengamatan

\begin{tabular}{|c|c|c|c|}
\hline No & Aspek Penilaian & $\begin{array}{l}\text { Jumlah mahasiswa } \\
\text { yang menunjukan } \\
\text { perilaku tersebut }\end{array}$ & $\begin{array}{c}\text { Persentase } \\
\text { mahasiswa yang } \\
\text { menunjukan perilaku } \\
\text { tersebut }\end{array}$ \\
\hline 1 & Mengerjakan TP setiap pertemuan & 32 & 29,09 \\
\hline 2 & Datang tepat waktu & 47 & 42,73 \\
\hline 3 & Mendengarkan penjelasan instruktur & 55 & 50,00 \\
\hline 4 & $\begin{array}{l}\text { Mengerjakan praktikum dengan baik } \\
\text { (minim kesalahan prosedur kerja) }\end{array}$ & 30 & 27,27 \\
\hline 5 & $\begin{array}{l}\text { Mengumpulkan laporan praktikum tepat } \\
\text { waktu }\end{array}$ & 25 & 22,73 \\
\hline 6 & Memperoleh nilai laporan parktikum > 75 & 43 & 39,39 \\
\hline
\end{tabular}

Berdasarkan Tabel 3 terlihat bahwa dari 110 orang mahasiswa persentase mahasiswa yang mengerjakan tugas pendahuluan masih sedikit hanya $29,09 \%$ atau 32 orang. Mahasiswa masih banyak yang terlambat datang paktikum, hanya $42,73 \%$ yang datang tepat waktu. Persentase mahasiswa yang mendengarkan penjelasan instruktur saat praktikum cukup besar yaitu $50 \%$ atau 55 orang, namun dalam 
mengerjakan praktikum masih banyak yang melakukan kesalahan, hanya $27,27 \%$ mahasiswa yang dapat mengerjakan praktikum dengan benar sesuai prosedur yang dijelaskan instruktur maupun yang tertulis didalam modul praktikum. Persentase mahasiswa yang mengumpulkan laporan praktikum tepat waktu hanya $22,73 \%$ atau 25 orang, bearti masih banyak mahasiswa yang tidak tepat waktu mengumpulkan laporan praktikum. Persentase mahasiswa yang memperoleh nilai laporan praktikum $>75$ hanya $39,39 \%$ atau 43 orang mahasiswa. Hal ini menunjukan mahasiswa belum cukup termotivasi dalam kegiatan praktikum.

Selanjutnya, pada kuisioner yang diisi mahasiswa, pertanyaan terkait kegiatan selama praktikum meliputi pertanyaan nomor 4,5,6,7 dan 8 . Hasil analisis kuisioner terkait kegiatan selama praktikum berlangsung dapat dilihat pada Gambar 2 berikut.

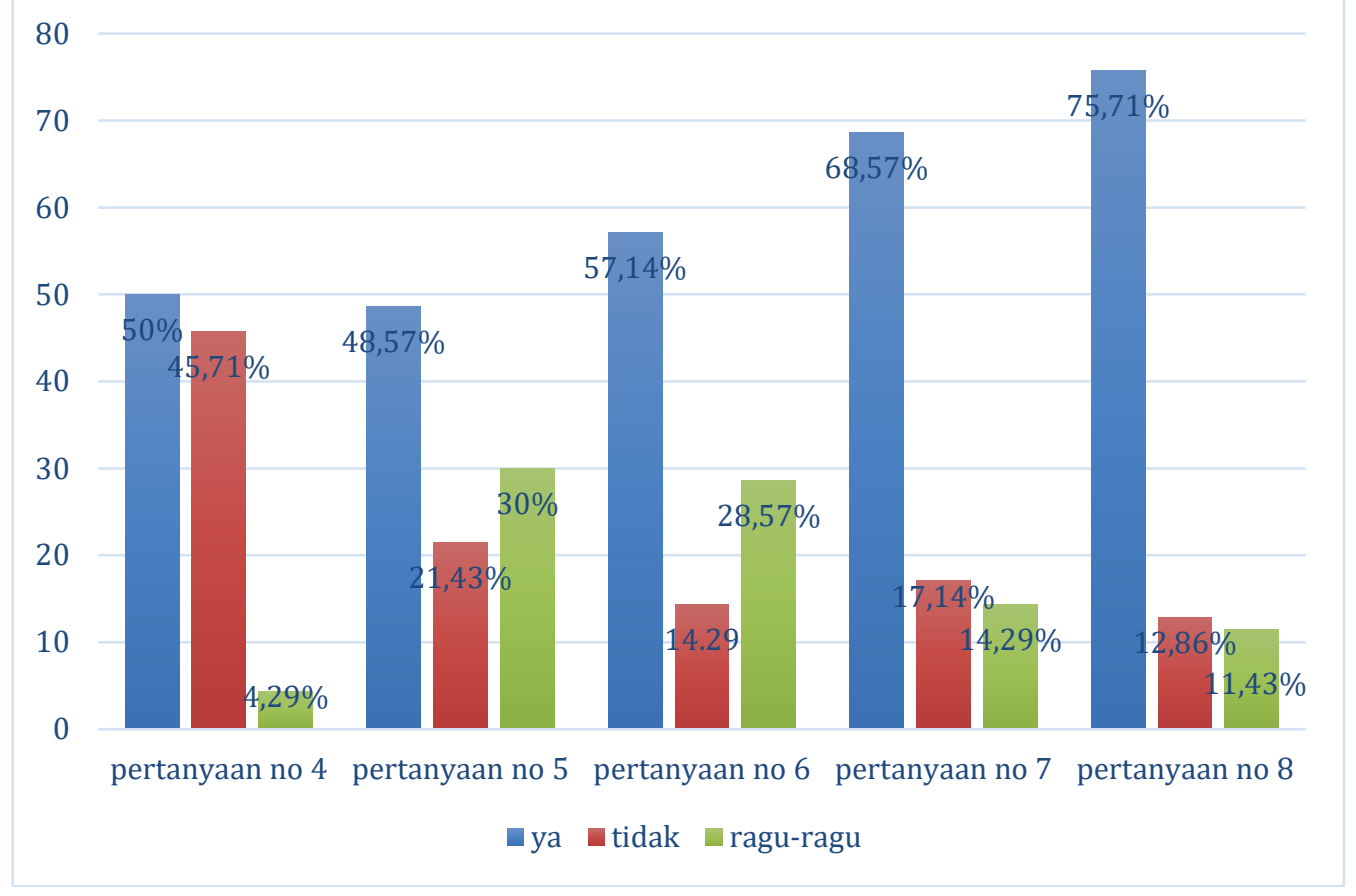

Gambar 2. Persentase tinjauan perilaku mahasiswa selama kegiatan praktikum

Berdasarkan Gambar 2 dapat dilihat bahwa persentase mahasiswa yang selalu berusaha datang tepat waktu sebelum praktikum dimulai 50\%, 45,71\% menyatakan tidak selalu datang tepat waktu sebelum praktikum dan $4,29 \%$ ragu-ragu. Persentase mahasiswa yang memahami modul praktikum yang digunakan dengan baik 48,57\%, dan 21,43\% menyatakan tidak memahami modul praktikum yang digunakan dengan baik sisanya 30\% ragu-ragu. Persentase mahasiswa yang menyatakan penjelasan penggunaan pada alat dan bahan praktikum cukup membantu dalam praktikum 57,14\%, 14,29\% tidak setuju dan $28,57 \%$ ragu-ragu. Persentase mahasiswa yang menyatakan prosedur praktikum dapat dipahami dengan baik cukup banyak 68,57\%, hanya $17,14 \%$ yang menyatakan tidak memahami prosedur praktikum dengan baik sisanya $14,29 \%$. Persentase mahasiswa yang menyatakan penjelasan dari instruktur dapat memudahkan dalam praktikum sebanyak $75,72 \%$, yang menyatakan tidak $12,86 \%$ dan sisanya $11,43 \%$ ragu-ragu.

Prosedur praktikum mendukung efektivitas sains serta pengalaman belajar yang memungkinkan siswa untuk mendapatkan yang terbaik dari itu (Etiubon, 2017). Senada dengan pendapat Hinampas, Murillo, Tan, \& Layosa (2018), bahwa keterampilan praktik jelas termasuk kompetensi individu dalam memanipulasi peralatan /peralatan tertentu. Merujuk pada hasil analisis, persentase mahasiswa yang menyatakan prosedur praktikum dapat dipahami dengan baik cukup banyak, namun persentase mahasiswa yang bisa mengikuti prosedur dengan baik lebih sedikit dibandingkan yang tidak dapat mengikuti prosedur. Hal ini menujukan mahasiswa masih kurang fokus dalam melakukan praktikum kimia dasar. 
3. Setelah Mengerjakan Praktikum

Pertanyaan terkait perilaku mahasiswa setelah praktikum meliputi pertanyaan nomor 9, 10, 11, dan 12. Persentase perilaku mahasiswa setelah kegiatan praktikum disajikan pada Gambar 3 berikut.

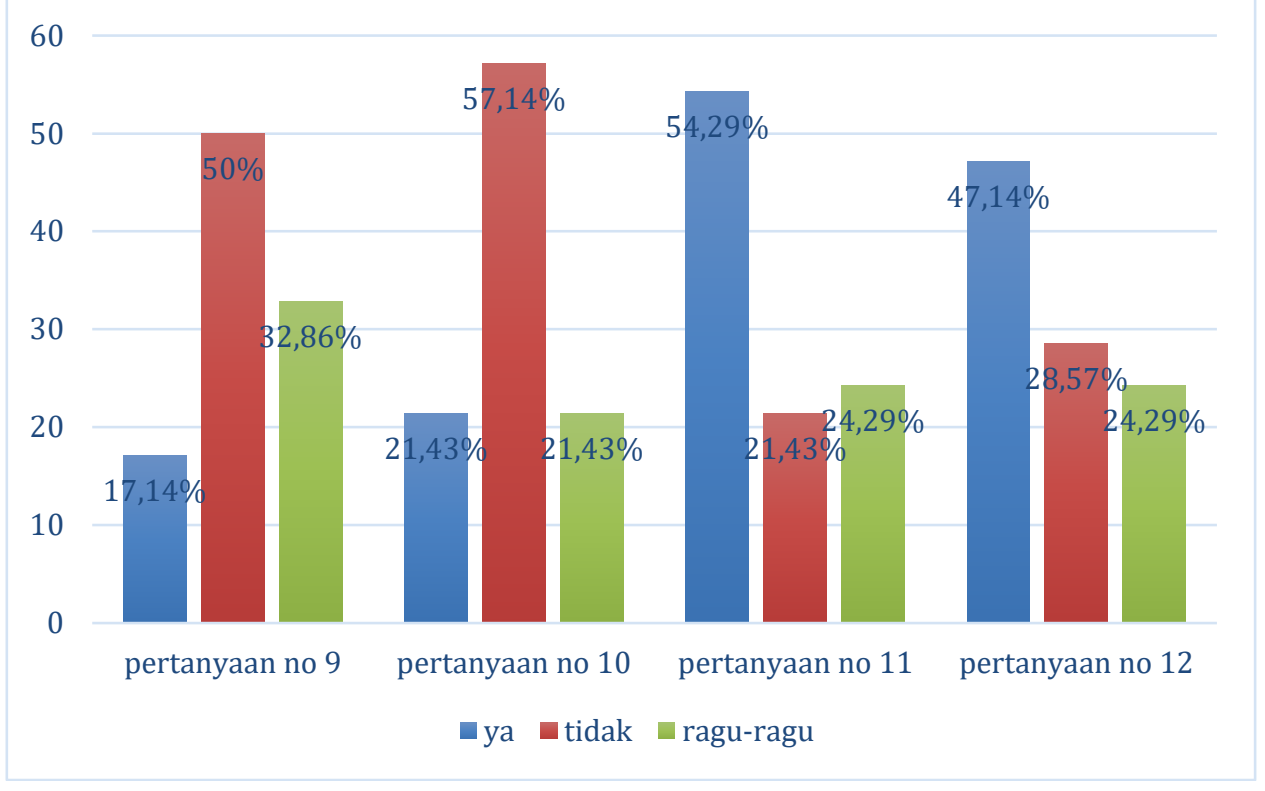

Gambar 3. Persentase perilaku mahasiswa setelah kegiatan praktikum

Berdasarkan Gambar 3 dapat diketahui bahwa 17,14\% mahasiswa menyegerakan pengerjaan laporan praktikum, namun lebih banyak persentase mahasiswa yang tidak segera mengerjakan laporan praktikum sebesar 50\%, sisanya 32,86\% ragu-ragu. Persentase mahasiswa yang mengerjakan laporan praktikum sendiri hanya $21,43 \%$, sementara persetase mahasiswa yang mengerjakan laporan praktikum berkelompok sebesar $54,29 \%$. Persentase mahasiswa yang menyatakan kegiatan praktikum memudahkan memahami konsep kimia $47,15 \%$, yang tidak setuju $27,57 \%$ sisanya ragu-ragu $24,29 \%$.

Hubungan antara representasi konsep dan aktivitas atau perilaku mahasiswa disimpulkan sebagai cerminan pemahaman konseptual terkait kegiatan kerja praktek (Sedumedi, 2017). Senada dengan pernyataan Sirhan (2007), bahwa mahasiswa yang memiliki motivasi untuk belajar dari kuliah memiliki konsekuensi penting untuk apa mereka memperhatikan, bagaimana mereka memproses informasi, dan bagaimana mereka bereaksi terhadap kuliah. Merujuk pada hasil analisis, persentase mahasiswa yang menyegerakan pengerjaan laporan praktikum masih rendah hanya $17,14 \%$. Mahasiswa cenderung menunda-nunda pengerjaan laporan praktikum. Dalam mengerjakan laporan praktikum persentase mahasiswa yang berkelompok lebih banyak daripada mahasiswa yang mengerjakan laporan praktikum sendiri. Selanjutnya, persentase mahasiswa yang menyatakan kegiatan praktikum memudahkan memahami konsep kimia 47,15\%, namun persentase mahasiswa yang memperoleh nilai laporan praktikum $>75$ sebesar 39,39\%. Hal ini menunjukan mahasiswa masih kurang memotivasi diri dalam kegiatan praktikum.

\section{SIMPULAN DAN SARAN}

Berdasarkan penelitian yang dilakukan dapat disimpulkan bahwa: (1) Sebelum mengikuti kegiatan praktikum Kimia Dasar mahasiswa masih kurang mempersiapkan diri, yaitu hanya $28,57 \%$ mahasiswa membaca modul sebelum melakukan praktikum, 37,14\% mahasiswa mengerjakan tugas pendahuluan dan 21,43\% mahasiswa yang menjaga kesiapan fisik (istirahat cukup dan sarapan sebelum praktikum). (2) Ketika praktikum Kimia Dasar berlangsung mahasiswa yang datang tepat waktu $42,73 \%$, persentase mahasiswa yang menyatakan prosedur praktikum dapat dipahami dengan baik cukup banyak 68,57\%, namun 27,27\% mahasiswa yang dapat mengerjakan praktikum dengan benar sesuai prosedur yang dijelaskan instruktur maupun yang tertulis didalam modul praktikum. (3) Setelah praktikum selesai persentase mahasiswa yang menyegerakan pengerjaan laporan praktikum masih rendah hanya $17,14 \%$, persentase mahasiswa yang menyatakan kegiatan praktikum memudahkan memahami konsep kimia $47,15 \%$, namun persentase mahasiswa yang memperoleh nilai laporan praktikum > 75 sebesar 39,39\%. Hal ini menunjukan mahasiswa masih kurang memotivasi diri dalam kegiatan praktikum 
Diharapkan penelitian ini memberi gambaran agar mahasiswa memperbaiki cara belajar yang dipakai selama ini juga mejadi pertimbangan bagi dosen dan instruktur untuk memperbaiki sistem pengajaran dan praktikum agar kualitas pendidikan dapat ditingkatkan.

\section{DAFTAR RUJUKAN}

Arianti, W., Qaddafi, M., \& Zulkarnaim. (2017). Pengembangan Penuntun Praktikum Kimia Dasar untuk Mahasiswa Pendidikan Biologi Universitas Negeri Alauddin Makassar. Jurnal Biotek, 5(2), 53-72.

Copriady, J. (2015). Practical Implementation of Practical Chemistry Among Secondary School Teachers. Asian Journal of Scientific Research, 8(1), 22-40.

Etiubon, R. U. N. M. (2017). Effects of Practical Activities and Manual on Science Students' Academic Performance on Solubility in Uruan Local Education Authority of Akwa Ibom State. Journal of Education and Practice, 8(3), 202-209.

Hinampas, R. T., Murillo, C. R., Tan, D. A., \& Layosa, R. U. (2018). Blended learning approach: Effect on students' academic achievement and practical skills in science laboratories. Lnternational Journal of Scientific and Technology Research, 7(11), 63-69.

Lubis, L. T., Silaban, R., \& Jahro, I. S. (2016). Pengembangan Penuntun Praktikum Kimia Dasar I Terintegrasi Pendekatan Inkuiri. Jurnal Pendidikan Kimia, 8(2), 20-30.

Maknun, D. (2015). Evaluasi Keterampilan Laboratorium Mahasiswa Menggunakan Asesmen Kegiatan Laboratorium Berbasis Kompetensi Pada Pelaksanaan Praktek Pengalaman Lapangan (Ppl). Jurnal Tarbiyah, 22(1), 21-47.

Pratono, A., Sumarti, S. S., \& Wijayati, N. (2018). Contribution of Assisted Inquiry Model of E-Module to Students Science Process Skill. Journal of Innovative Science Education, 7(1), 62-68.

Raharjo, R., \& Harjanto, S. (2017). Penanganan Alat Dan Bahan Yang Baik Dalam Rangka Menunjang Kegiatan Di Laboratorium Kimia. Metana, 13(2), 58.

Rahayu, C., \& Festiyed. (2018). Validitas Perangkat Pembelajaran Fisika Sma Berbasis Model Pembelajaran Generatif Dengan Pendekatan Open- Ended Problem Untuk Menstimulus Keterampilan Berpikir Kritis. Jurnal Pendidikan Fisika, 7(1), 1-6.

Rudi, K. (2015). Penerapan Praktikum PEER-Model Dalam Mata Kuliah Fisika Dasar Untuk Melatihkan Scientific Skills Mahasiswa Prodi Fisika Unesa. Seminar Nasional Fisika Dan Pembelajarannya 2015, 123-132.

Sari, S., Dayana, D., \& Farida, I. (2018). Analisis Profil Manajemen Laboratorium Dalam Pembelajaran Kimia Di Sma Wilayah Sumedang. Jurnal Tadris Kimiya, 3(1), 248.

Sedumedi, T. D. T. (2017). Practical work activities as a method of assessing learning in chemistry teaching. Eurasia Journal of Mathematics, Science and Technology Education, 13(6), 1765-1784.

Sirhan, G. (2007). Learning Difficulties in Chemistry: An Overview. Journal of Turkish Science Education, $4(2), 2-20$.

Wahyudiati, D. (2016). Analisis Efektivitas Kegiatan Praktikum Sebagai Upaya Peningkatan Hasil Belajar Mahasiswa. Jurnal Tatsqif, 14(2), 143-168. https://doi.org/10.20414/jtq.v14i2.27

Zakirman. (2017). Kelompok gaya belajar reflektor menurut teori Honey Mumford dalam paradigma perpustakaan. Shaut Al-Muktabah Jurnal Perpustakaan, Arsip Dan Dokumentasi, 8(2), 133-142.

Zakirman, Lufri, \& Khairani. (2018). Factors Influencing the Use of Lecture Methods in Learning Activities : Teacher Perspective. Advances in Social Science, Education and Humanities Research, 178(ICoIE 2018), 4-6.

Zakirman, \& Rahayu, C. (2018). Popularitas WhatsApp sebagai media komunikasi dan berbagi informasi akademik mahasiswa. Shaut Al-Maktabah: Jurnal Perpustakaan, Arsip Dan Dokumentasi, 10(1), 2738. 